\title{
Numerical simulation of co-incineration of sewage sludge and municipal solid waste in municipal solid waste incinerator
}

\author{
Haichuan Wang, Yanfen Liao, Xiaoqian Ma, Xianghao Zeng \\ Guangdong Provincial Key Laboratory of Clean Energy Utilization, South China University of Technology,Guangzhou,510641
}

\begin{abstract}
Incineration is widely used as an important method of sludge and garbage utilization and harmless treatment. The simulations of co-incineration of sludge and municipal solid waste are conducted by computational fluid dynamics method(CFD) in a MSW incinerator. The study focuses on the effect of mixing proportion, moisture content of sludge, excess air coefficient and primary and secondary air distribution ratio on the combustion progress. Simulation results indicate that the combustion temperature of furnace decreases rapidly with the increase of the mixing proportion and moisture content of sludge, which is mainly because the moisture content of sludge is higher than that of MSW as well as its low calorific value. As a result, it is recommended that the water content and mixing ratio of sludge would be controlled below $40 \%$ and $7 \%$ respectively. Therefore, the fresh sludge should be dried before entering the furnace.
\end{abstract}

\section{Introduction}

With the rapid development of the urban economy, the treatment capacity required of municipal solid waste(MSW) and sewage sludge is increasing year by year at a tremendous rate around the world. In particular, the traditional landfill method has a great damage to the environment, because garbage consists of many complex harmful components including viruses, parasites and heavy mental compounds[1,2]. Meanwhile, sewage sludge is a by-product of waste-water treatment, which contains a large number of harmful ingredients including pharmaceuticals, poly-cyclic aromatic hydrocarbons, pathogens, and heavy metals[3]. As an important means of resource utilization and harmless disposal, the coincineration technology of MSW and sludge has been paid attention widely, which was applied widely in developed countries and some emerging economies including China[4,5].

With the rapid improvement of residents' living standards, the number of taking out packaging boxes, express packages, and plastic products in urban domestic garbage is increasing. Consequently, the lower heating value(LHV) of domestic garbage is increasing, especially in developed cities where residents have relatively high incomes in China[6,7]. In some cases, the LHV even approaches the upper limit of incinerator design, which seriously affects the stable and safe operation of MSW incinerators. It provides the possibility and commercial application value of sludge mixing in MSW incinerator.Computational fluid dynamics (CFD) is widely used in the design and operation optimization of large-scale combustion equipment, including waste incinerator and coal-fired boiler[8,9]. The CFD technique has unique advantages over the analytical calculations, including ease of use, time efficiency, and the ability to readily change [10-13]. In brief, the research of scholars shows that the coincineration of sludge and garbage has a perspective future.

In this paper, co-incineration of municipal sewage sludge and garbage was studied in a $350 \mathrm{t} / \mathrm{d}$ municipal solid waste furnace in South China. Temperature distribution in the furnace were calculated to describe the combustion process of the furnace in order to determine the best operating parameters.

\section{Materials and method}

\subsection{Numerical simulation method}

In this study, the whole co-incineration process of MSW and sludge is divided into bed solid combustion process and gas phase combustion process. The drying, pyrolysis and combustion process of MSW in the bed were simulated by Flic software[5,14,15]. The combustion results outside the bed were simulated by Fluent software. The solid-phase combustion results calculated by Flic were imported into Fluent as boundary conditions to establish the coupling calculation of solidphase combustion and gas-phase combustion. This procedures were continued until the gas temperature did not change obviously with more iterations. In detail, the scaled residuals for continuity, velocity and energy are less than 1e-3, 1e-3 and 1e-6 respectively.

Mass, momentum, energy, turbulence and species transport conservation equations are solved to achieve a solution[16]. The standard k- $\varepsilon$ model was used to simulate the turbulent process in the furnace[17]. The 
combustion process in the incinerator was simulated by the finite rate eddy dissipation model (FR/EDC). The steady-state governing equations were solved using SIMPLE algorithm. P1 model was used to simulate the radiation process[18]. The component transport model was used to describe the chemical reactions in which particles participate[19].

The co-combustion process of garbage and sludge in a garbage incinerator is a complicated process. The convergence of digital calculations and the accuracy of numerical simulation results should be considered comprehensively[20]. Consequently, the simplification and assumptions for the numerical calculation of fuel combustion process on the bed were made as follows:

(1)Sludge and garbage were fully mixed and uniformly distributed on the grate, and both enter the incinerator at the same time for combustion.

(2)The combustion fuel consisted of water, volatile, fixed carbon and ash.[12,13]

(3)The gas separated from the volatile was composed of water vapor, $\mathrm{CH}_{4}, \mathrm{CO}, \mathrm{H}_{2}$ and $\mathrm{CO}_{2}$ mainly[17].

(4) In the combustion process, the solid particles were broken, the ash was melted. In addition, the slagging wad ignored, and the gas was regarded as the ideal gas[21].

\subsection{Models and computational conditions}

The research object is a 350t/D MSW incinerator in South China. The daily treatment capacity of the MSW incinerator with moving grate involved in this study is 350 tons per day. The schematic structure of MSW incinerator is shown in Fig.1. The boiler body is about 18.5 meters high .The first flue is about $5.8 \mathrm{~m}$ long and $5.5 \mathrm{~m}$ wide.

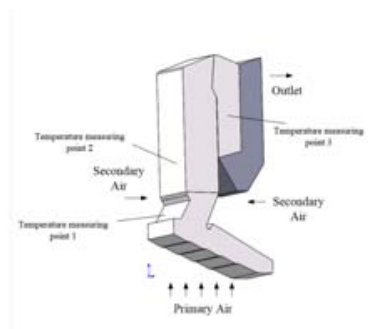

(a)The schematic structure

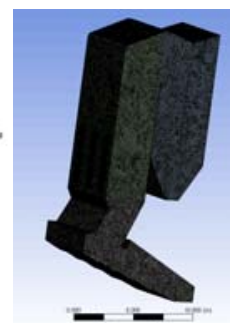

(b)The mesh of incinerator
Fig. 1. The model of MSW incinerator.

The air required for fuel combustion includes primary air (PA) and secondary air (SA). The primary air enters from the five stage grate, which is 10 meters long. The secondary air enters from the secondary air outlets on the left and right sides in the middle of the furnace. In order to improve the air distribution of the bed, the bottom grate is provided with a flame bending angle.

Because the incinerator body of MSW is relatively complex, the incinerator is divided into four areas when meshing, including the bottom grate and burner, the first flue and the second flue. The mesh model adopts tetrahedral structured mesh based on adaptive geometry model. The total number of grid is about 2.18 million, where the important parts were refined, such as grate and nozzles of PA and SA. The quality of grid is excellent, which meets the requirements of numerical calculation by Fluent. Eleven secondary air pipes are arranged on both sides of the furnace. The grate speed under all working conditions is $12 \mathrm{~m}$. There are five nozzles below the grate, where the air distribution ratio of the five-stage air chamber is $0.15: 0.25: 0.35: 0.15: 0.10$.

Through the numerical simulation test above, the best mixing proportion of the $350 \mathrm{t} / \mathrm{D} \mathrm{MSW}$ incinerator and the proper moisture content of the mixed sludge was determined through the analysis of temperature field correspondingly. Aiming to the recommended mixing ratio and water content, the optimization of operating parameters is also discussed. Based on the above research, the best excess air coefficient and the best air distribution mode were determined as well.

\subsection{Materials}

The MSW and sewage sludge samples considered in this research were obtained from an MSW incineration plant and a sewage treatment plant in Guangzhou, China. Table 1 shows the results of the proximate and ultimate analysis of the MSW and sewage sludge. The mass sensitivity of the attached micro-balance is less than \pm $0.1 \mu \mathrm{g}$, and the temperature sensitivity is less than \pm $0.5^{\circ} \mathrm{C}$.

Table 1. The ultimate analysis and proximate analysis of the MSW and the wet sludge.

\begin{tabular}{|c|c|c|c|c|c|}
\hline $\begin{array}{l}\text { Ultimate } \\
\text { analysis(wt\%) }\end{array}$ & $\mathrm{C}$ & $\mathrm{H}$ & $\mathrm{O}$ & $\mathrm{N}$ & $\mathrm{S}$ \\
\hline MSW & 24.00 & 3.10 & 13.00 & 0.09 & 0.21 \\
\hline Sludge & 30.18 & 4.73 & 59.97 & 5.12 & 0 \\
\hline $\begin{array}{l}\text { Proximate } \\
\text { analysis(wt\%) }\end{array}$ & Moisture & Volatile & $\begin{array}{c}\text { Fixed } \\
\text { Carbon }\end{array}$ & Ash & $\mathrm{LHV}$ \\
\hline Sludge & 76.67 & 11.20 & 1.44 & 10.69 & $\begin{array}{c}1012 \\
\mathrm{~J} / \mathrm{kg}\end{array}$ \\
\hline
\end{tabular}

As shown in Table 1, the LHV of MSW is about $9000 \mathrm{~J} / \mathrm{kg}$ and the LHV of sewage sludge is about $1012 \mathrm{~J} / \mathrm{kg}$. Because the thermal properties of sewage sludge and garbage are significantly different, the coincineration process of MSW and garbage will have a considerable impact on the daily operation of a garbage incinerator apparently. The increase of sludge mixing ratio and water content will lead to a decrease in fuel calorific value, which may lead to the deterioration of fuel combustion and threaten the safe and stable operation of the incinerator. Generally, the higher the moisture in the sludge, the greater the decrease in the calorific value is. It is necessary to restrict the mixing ratio and moisture content of sewage sludge. There may be an optimal mixing ratio and water content so that the mixing of sludge does not threaten the safe operation of the garbage furnace remarkably.

\section{Results and discussion}

\subsection{MSW mono-combustion characteristic}




\subsubsection{Model reliability verification}

Table 2. The comparison of numerical simulation and actual operation data

\begin{tabular}{|c|c|c|c|}
\hline Parameter & $\begin{array}{c}\text { Actual } \\
\text { Results }\end{array}$ & $\begin{array}{c}\text { Simulatio } \\
\text { n Results }\end{array}$ & Error \\
\hline Main combustion area & $1472.15 \mathrm{~K}$ & $1450.02 \mathrm{~K}$ & $1.35 \%$ \\
\hline $\begin{array}{c}\text { First flue measurement } \\
\text { point }\end{array}$ & $1236.30 \mathrm{~K}$ & $1210.50 \mathrm{~K}$ & $2.08 \%$ \\
\hline $\begin{array}{c}\text { Second flue } \\
\text { measurement point }\end{array}$ & $1007.75 \mathrm{~K}$ & $994.56 \mathrm{~K}$ & $1.30 \%$ \\
\hline $\begin{array}{c}\mathrm{O}_{2} \text { fraction of outlet } \\
(\text { wt } \%)\end{array}$ & $7.30 \%$ & $7.52 \%$ & $2.93 \%$ \\
\hline
\end{tabular}

Three temperature measuring points were respectively arranged in the main combustion area, the top of the first flue and the middle of the second flue separately. The field data was the average value of 24 hours of stable operation under the basic working condition in the actual operation of the garbage furnace.

It was found that the error of numerical simulation results is within $5 \%$ of the actual engineering requirements, which means the results of measurement data of actual operation are consistent. The error is probably caused by the fact that it is impossible for the actual garbage to enter the furnace completely and evenly, and this has not be taken into consideration in the simulation.

Overall, comparison between simulated data and actual data showed that the simulation of the temperature field of MSW incinerator are reliable by using the coupling calculation of Flic and Fluent. The temperature of three different measuring points of the MSW incinerator was consistent with the actual temperature to verify the rationality and prediction validity of the mathematical model.

\subsubsection{Simulation of MSW mono-combustion}

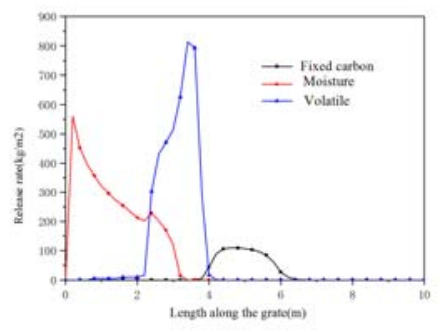

(a) Bed solid combustion results
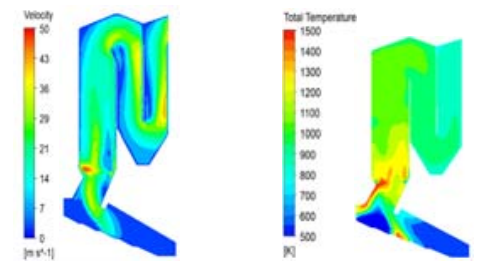

(b)Velocity profile (c) Temperature profile

Fig. 2. Profiles of temperature and velocity fields of monocombustion.
Profiles of temperature and velocity fields of monocombustion are shown in Fig.2. The combustion process of the bed consists of fixed carbon burning, water vapor evaporation, and the release of volatile[22]. Compared with other fuels like coal, it takes a longer time and distance to evaporate the water in the fresh waste because water content of untreated waste is relatively high. From $0 \mathrm{~m}$ to $2.5 \mathrm{~m}$, the water evaporation process is completed. It is mainly affected by PA and radiant heating of the furnace arch. In addition, the back-flow area formed by the front arch's suppression of the primary airflow could further strengthen the drying effect, and the moisture on the surface of the garbage precipitates and completes evaporation. Between $2.5 \mathrm{~m}$ and $3.75 \mathrm{~m}$, the combustion process is most intense. The results showed that combustion was the most intense at $3.75 \mathrm{~m}$; the fixed carbon combustion ended from $6.25 \mathrm{~m}$. Between $4 \mathrm{~m}$ and $6 \mathrm{~m}$, the grate combustion process enters a stable combustion process. The combustion process at the bottom of the bed and the speed of smoke overflow are mainly affected to the volatiles release, combustion of fixed carbon, and the proportion of gases and primary air produced. Correspondingly, the appearance of the high-temperature zone at the bottom of the grate is mainly affected to the rapid combustion of fixed carbon. $\mathrm{CO}_{2}$ is mainly produced in the pyrolysis combustion and fixed carbon combustion processes, and its content reaches the maximum mass fraction in the fixed carbon combustion stage. In short, the actual solid combustion process is in accordance with the numerical simulation results

The PA enters from five air chambers and brings the gas generated from fixed carbon combustion and volatiles releases of fresh garbage into the main combustion area. The secondary air and primary air together form a swirl, which increases the turbulence of flue gas. The SA forms a strong turbulence area, which is conducive to the full contact of combustible components and air. Meanwhile, the existence of secondary air prolongs the residence time of combustible components in the MSW incinerator, which is beneficial to further improving combustion efficiency. The analysis of velocity field shows that the spiral rise of flue gas in the upper part of the first flue can improve the residence time of flue gas in the flue and the heat exchange efficiency of the water-cooled wall.

Figure 2(c) shows the profile of the temperature field in the combustion furnace of MSW without mixed sludge by CFD analysis, to describe the combustion process in the incinerator. Heat is transferred to cooled wall with the increase in height, which results in temperature decreases sharply. The main combustion zone of the combustion process is mainly concentrated on the two outlets of the burner and the central area of the furnace. Fresh garbage enters the furnace through the grate, and the highest temperature of the grate can reach $1300 \mathrm{~K}$ at least. Secondary combustion occurs at the secondary air outlet through the combined action of secondary air and primary air, aiming to the full combustion of unburden components yet.

In summary, the results of numerical simulation and actual operation data are consistent. It indicates that the 
coupling calculation of temperature field distribution in the incinerator by using Flic and Fluent has high reliability. This conclusion provides technical support for the next work, including the determination of the best working condition and the optimal adjustment of the working condition.

\subsection{Co-combustion of sewage sludge with MSW}

\subsubsection{Effects of mixing proportion}
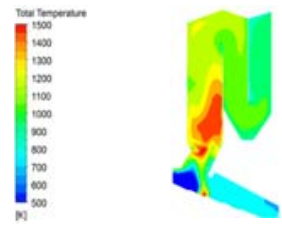

(a) $3 \%$

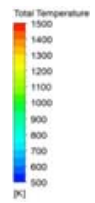

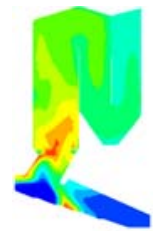

(b) $5 \%$

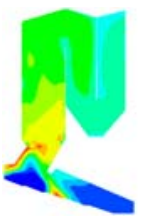

(d) $10 \%$

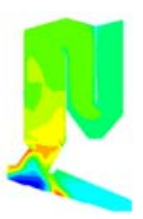

(e) $15 \%$
Fig. 3.The profiles of temperature $(K)$ in the furnace under different mixing proportions

Fig.3 shows the numerical simulation results of the sludge temperature field under different mixing proportions. It indicates that the combustion process of the furnace with different mixing proportions is similar, and the high-temperature area is concentrated in the burner area and the secondary air outlet. The position of the high temperature zone in the grate moves backward continuously with the increase of sludge content. With the increase in the proportion of sludge, the temperature of the main combustion zone decreased. Compared with the a small amount of sludge co-combustion, the area with temperature higher than $1500 \mathrm{~K}$, which has negative effect on the stable combustion. It is mainly because the heat value of sludge is significantly lower than that of MSW as well as the evaporation of water.

As shown in Fig.4, the combustion of fixed carbon in sludge and garbage causes the temperature to rise above the grate with a height of about 7 meters. As the primary air drives the combustible components to the middle of the furnace, at the secondary air outlet of about $9 \mathrm{~m}$, the combustible gas will conduct secondary combustion under the disturbance of the secondary air.

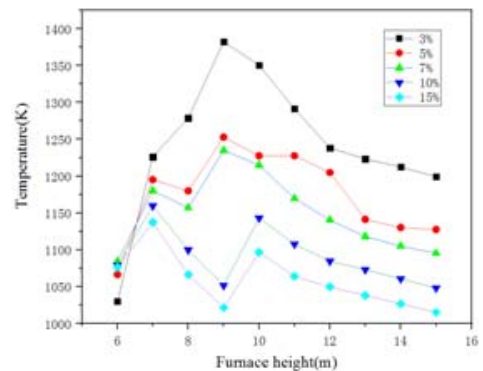

Fig. 4. The average temperature of cross section along with height under different mixing proportions

With the increase of the mixing ratio, the combustion temperature in the main combustion zone decreases obviously. The secondary combustion process in the burnable component furnace delays significantly as well. On the one hand, because the fixed carbon content of sludge is lower than that of domestic waste, the position of volatile release and coke combustion at the grate has a backward shift with the increase of mixing proportion. On the other hand, the decrease of the overall temperature of the furnace directly leads to the remarkable decrease of the radiation effect of the flue gas on the front arch, and the primary combustion is delayed as well. In the same way, the secondary combustion process in the middle of the furnace is delayed due to the strong heat absorption of water evaporation in the sludge[23]. Considering the requirements of combustion stability and economy, it is recommended the proportion of sludge mixed in incinerator should be controlled within $7 \%$. The results indicate that the temperature of the furnace main combustion zone decreases as the proportion of mixed sludge and sludge moisture content increase, due to the fact that the moisture content of sludge is higher than that of MSW in general. It is found that appropriate air distribution ratio and excess air coefficient can improve the airflow organization in the furnace. Specifically, the garbage and sludge are fully burned in the bed and the middle of the furnace. As a result, the water content and mixing ratio of sludge should be controlled below $40 \%$ and $7 \%$ respectively.

\subsubsection{Effects of moisture content of sludge}

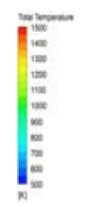

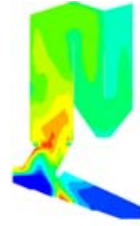

$40 \%$

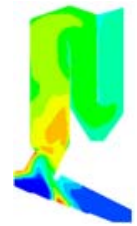

$60 \%$

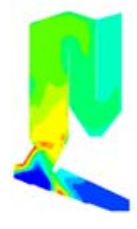

$80 \%$
Fig. 5. The profiles of temperature $(K)$ in the furnace under different moisture content

It could be observed that the combustion temperature in the furnace decreases as the moisture content of the sludge increases. The comparison of the cloud image of the temperature field shows that as the moisture content of the blended sludge increases, the area of the hightemperature area relatively decreases, and the concentration of fuel in the furnace decreases. Besides, the burning flame center height decreases simultaneously. Excessive moisture leads to deterioration of combustion and reduces the burnout rate of sludge and garbage. 


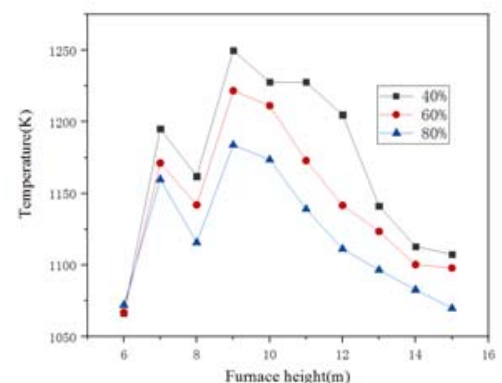

Fig. 6. The average temperature of cross-section along with height under different moisture content

As shown in Fig.6, increasing the water content of sludge has a greater impact on the secondary combustion in the middle of the furnace than the primary combustion that occurs at the bottom of the furnace. At a furnace height of about 9 meters, the combustion temperature in the case where the sludge moisture content is $80 \%$ is $100 \mathrm{~K}$ lower than the case where the moisture content is $40 \%$ at least.

In short, the sludge of excessively high moisture content can negatively affect the stable operation of the incinerator. It is necessary to limit the moisture content of the sludge. In summary, it is strongly recommended that the sewage sludge should be dried before being mixed and burned in the garbage incinerator so that its moisture content reaches below $60 \%$.

\section{Conclusion}

The study focus on the numerical simulation of cocombustion of sewage sludge and MSW by CFD. In this study, the operation state of MSW incinerator after mixing sludge was evaluated, in term of the temperature field of MSW incinerator mainly.

Firstly, the combustion results of single-component waste in the waste incinerator were studied, and the numerical simulation results were compared with the field operation data. It was found that through the coupled calculation of Flic and Fluent, heat transfer and combustion processes in the incinerator can be accurately simulated. Meanwhile, the error is within the range allowed by the engineering application.

Secondly, it was found that through the cthe mixed sludge, the temperature and the area of the hightemperature area in the incinerator has decreased significantly. This is mainly due to the strong heat absorption of the water evaporation in the sludge. As the sludge blending ratio increases, the heating value of the mixed fuel decreases, so the ignition point is delayed as well. Therefore, municipal sludge is recommended to be dried first, and the blending ratio should be controlled within $7 \%$.

\section{Acknowledgements}

The work was supported by Guangzhou Science and Technology Program key projects (201804020082), Guangdong Key Laboratory of Efficient and Clean Energy Utilization, South China University of technology
(2013A061401005), General Administration of Quality Supervision, State Administration for Market Regulation Science and Technology Project(No. 2017QK152 )

\section{References}

1. T. Brunner, J. Fluch, I. Obernberger, R. Warnecke, FUEL PROCESS TECHNOL 105, 154 (2013).

2. P. Stehlík, J CLEAN PROD 17, 919 (2009).

3. L. Chen, Y. Liao, X. Ma, Y. Niu, WASTE MANAGE 102, 645 (2020).

4. S. Fang et al., ENERG CONVERS MANAGE 101, 626 (2015).

5. Y. B. Yang, R. Newman, V. Sharifi, J. Swithenbank, J. Ariss, FUEL 86, 129 (2007).

6. D. Q. Zhang, S. K. Tan, R. M. Gersberg, J ENVIRON MANAGE 91, 1623 (2010).

7. H. Zhou, A. Meng, Y. Long, Q. Li, Y. Zhang, Renewable and Sustainable Energy Reviews 36, 107 (2014).

8. Q. Wu, Y. Dong, J. Rao, Vibroengineering PROCEDIA 28, 165 ( 2019).

9. H. Cheng, Y. Zhang, A. Meng, Q. Li, ENVIRON SCI TECHNOL 41, 7509 (2007).

10. T. B. Bechtel, J HYDRAUL ENG 129, 153 ( 2003).

11. Z. Hu, E. Jiang, X. Ma, FUEL 245, 160 (2019).

12. H. Lin, X. Ma, WASTE MANAGE 32, 561 (2012).

13. A. C. H. Lai, A. W. Law, INT J NUMER METHOD H 29, 504 (2019-02-04, 2019).

14. C. Ryu et al., FUEL 85, 1039 (2006).

15. Z. Xia, J. Li, T. Wu, C. Chen, X. Zhang, WASTE $M A N A G E$ 34, 1609 (2014).

16. C. A. Bermúdez, J. Porteiro, L. G. Varela, S. Chapela, D. Patiño, FUEL PROCESS TECHNOL 198, 106219 (2020).

17. L. Lu, T. M. Ismail, Y. Jin, M. Abd El-Salam, K. Yoshikawa, FUEL PROCESS TECHNOL 154, 52 (2016).

18. B. Zhang, J. He, C. Hu, W. Chen, PROCESSES 7, 649 (2019).

19. A. Fluent, Ansys Fluent Theory Guide.(2011), pp. 724-746.

20. Y. B. Yang, H. Yamauchi, V. Nasserzadeh, J. Swithenbank, FUEL 82, 2205 (2003).

21. Y. B. Yang, Y. R. Goh, R. Zakaria, V. Nasserzadeh, J. Swithenbank, WASTE MANAGE 22, 369 (2002).

22. J. Werther, T. M. Ogada, Progress in Energy \& Combustion Science 25, 55 (1999).

23. K. Lei, R. Zhang, B. Ye, J. Cao, D. Liu, WASTE $M A N A G E$ 101, 1 (2020) 